\title{
Comparison of communication and personal characteristics of living kidney donors and a matched quota sample
}

\author{
Smith SW, Hitt R, Nazione S, Lauckner C, Park HS, Sung R, \\ Leichtman A. Comparison of communication and personal \\ characteristics of living kidney donors and a matched quota sample.
}

Abstract: Deceased organ donation does not meet the need for kidney transplants. Thus, it is important to examine topics relevant to kidney donors such as communication leading to the donation decision and donor characteristics. This study reports personal characteristics and communication leading to the decision to donate among living kidney donors and a demographically matched quota sample. Donors had higher scores for compassion, while non-donors reported more volunteerism. Donors and non-donors did not differ in conversation or conformity orientations of family communication styles. Only $4.7 \%$ of donors reported being asked to donate directly. Matched respondents reported feeling more comfortable than unsettled with the idea of being asked directly and indicated a preference to learn of the need directly or indirectly, giving them the option to volunteer. The majority of donors were giving to family members and friends, and the matched sample indicated greater willingness to donate to immediate family members, followed by friends. Practical implications of the findings are offered.

\author{
Sandi W. Smith ${ }^{\mathrm{a}}$, Rose Hitt ${ }^{\mathrm{b}}$, \\ Samantha Nazione ${ }^{\mathrm{a}}$, Carolyn \\ Lauckner ${ }^{\mathrm{c}}$, Hee Sun Park ${ }^{\mathrm{a}}$, Randall \\ Sung $^{d}$ and Alan Leichtman ${ }^{d}$ \\ aDepartment of Communication, Michigan \\ State University, East Lansing, MI, USA, \\ ${ }^{b}$ Department of Humanities and \\ Communication, Albany College of Pharmacy \\ and Health Sciences, Albany, NY, USA, \\ 'Department of Telecommunication, Michigan \\ State University, East Lansing, MI, USA and \\ dUniversity of Michigan Health Systems, Ann \\ Arbor, MI, USA
}

Key words: kidney donation communication kidney donation decision - kidney transplant - organ donation - organ donation communication

Corresponding author: Sandi W. Smith, Department of Communication, Michigan State University, 573 Communication Arts \& Sciences, East Lansing, MI 48824, USA. Tel.: 517-353-3715; fax: 517-432-1192; e-mail: smiths@msu.edu

Conflict of Interest: None.

Accepted for publication 24 July 2012
The need for organ donors in the United States is great, with over 124000 people waiting for a transplant organ. Over 98000 of those are waiting for a kidney (1). In 2011, 16814 kidney transplants were performed, 11043 of which were from deceased donors and 5771 of which were from living donors. However, over 7428 kidney transplant candidates were removed from the list in 2011 because they either died (4921) or became too sick (2507) to receive a transplant. Clearly, deceased donors cannot meet our nation's current demand for donor kidneys. Live kidney donation, the process whereby a living individual gives one kidney, is an established alternative to deceased donor transplantation and provides better outcomes for the recipient $(1,2)$.
The living donation process requires that a donor is informed of the recipient need and then makes a decision to offer to donate. Thus, personal characteristics of the living kidney donor and characteristics of the communication leading to the donation decision are critical to understand. Limited research of this type has been performed, although research from the perspective of the recipient is more frequent (3-5). This study attempts to understand living donor personal characteristics, communication, and the decision to donate by comparing them to a demographically matched quota sample. The remainder of this study will discuss the process of living kidney donation, personal characteristics of donors, communication about the process, and decision-making about liv- 
ing kidney donation before detailing the methods, results, and conclusions.

\section{Living kidney donation}

The ideal live organ donor should be competent, willing to donate, free of coercion, medically and psychosocially suitable, fully informed of the risks and benefits as a donor, and fully informed of the risks, benefits, and alternative treatment available to the recipient. Benefits to the donor and the recipient must be greater than risks associated with the transplantation procedure $(6,7)$. Assessment of the attributes noted above and communication to inform potential donors of risks, benefits, and possible alternative treatment therapies for recipients takes place at transplant centers such as the one where this research took place.

Despite current programs, one study found that more than $75 \%$ of potential kidney recipients wanted more education about living donation (8), and both recipients and donors thought that better education about asking for donations, donor motivations, and the transplant experience would be helpful for those considering living donation (9). To provide this type of information, research is needed exploring personal characteristics of donors and their preferences for certain types of communication as they engage in decision-making about donation. It is particularly important to compare the personal and communication characteristics of living kidney donor volunteers with a matched sample of the general public to see if they differ. This information is important to provide desired education about donor motivations and requests for donations. One of the very few studies comparing living donors and others compared the donors to their own relatives (10). To further this line of research, the present research compared donor volunteers with a demographically matched quota sample.

\section{Living donor altruistic characteristics}

Kopfman and Smith's organ donation willingness model (11), and research by Morgan and Miller (12) found that the personal characteristic of altruism was an important predictor of attitudes toward donation, which led to intent to donate. This research was based on donation after death; however, scholars have also found that altruism and compassionate love for others characterize living donors as well, especially those who offer to donate to an unrelated stranger (13-15). Currently unknown, however, is whether altruism or ompassionate love is higher for living kidney donor volunteers than for others with similar characteristics but who are not current living kidney donor volunteers. Therefore, the first research question was posed:

RQ1: Do living kidney donor volunteers have higher compassionate love than their demographically matched peers?

Volunteer activities are another gauge of altruism $(16,17)$, and they are less subjective than selfrated love for humanity. These behaviors are altruistic because they "are voluntary acts of giving or sharing intended to help others" (18). The second research question was posed:

RQ2: Do living kidney donor volunteers engage in significantly more volunteer activities than their demographically matched peers?

\section{Communication about living kidney donation}

Communication is inherent in the living donation process (6). The need for an organ must become known to prospective donors for action to take place, and once the need is known, the decision to donate is a process involving communication. Living donors often talk with families and members of their social networks to help them decide whether to donate. Once donors decide to donate, they communicate with transplant center personnel (19), and donors often communicate directly with the intended recipient (20). Because of the amount and breadth of communication required in this process, it is possible that people who are comfortable with communication are more likely to go through the process to become living kidney donor volunteers. Differential family communication patterns could lead to more comfort with communication.

Park et al. (21) investigated the role of family communication patterns on intention to register as an organ donor and on family discussion of those wishes. They adopted the family communication pattern construct that types families by their conformity orientation or conversation orientation to communication $(22,23)$. The conformity-orientation dimension refers to "the degree to which family communication stresses a climate of homogeneity of attitudes, values, and beliefs" (24). The conversation-orientation dimension is defined as "the degree to which families create a climate in which all family members are encouraged to participate in unrestrained interaction about a wide array of topics" (24). Park et al. (21) found that the positive relationship between attitude toward organ donation and willingness to engage in family discussion about organ donation was weaker for 
those with stronger conformity orientations and stronger for those with stronger conversation orientations. One question remaining on this topic is whether living kidney donor volunteers have a higher conversation orientation and a lower conformity orientation to family communication than those in a demographically matched sample, which is explored in the third research question:

RQ3: Do living kidney donor volunteers have a higher conversation orientation and a lower conformity orientation to family communication than those in a demographically matched sample?

Another dimension of communication is the method by which the potential living kidney donor becomes aware of the recipient's need. Previous research has found that recipients are hesitant to ask potential donors directly $(5,25)$. Therefore, a question that needs to be asked of the demographically matched sample is how comfortable they are with being asked directly to donate.

RQ4: What is the level of comfort of the demographically matched sample with being asked directly to donate a kidney?

A comparison that can be made is to ask the volunteers how they were asked to become donors or became aware of the need of the recipient, and to ask a demographically matched sample their preferences regarding different methods for learning about the recipient's need. Methods of discovering the need could be direct requests, learning indirectly through others, mass letters or emails, or not wanting to know at all. These issues lead to the following question:

RQ5: By what methods have living kidney donor volunteers found out about the need for donation and what are the methods preferred by a demographically matched sample?

\section{Decision-making about living kidney donation}

Ultimately, potential donors have to decide whether to go forward with testing that will determine whether they will be accepted as living kidney donors. All of the volunteers in the sample made that decision, but it remains to be seen what proportion of the demographically matched sample believe that they would make that decision:

RQ6: What proportion of the demographically matched sample believes that they would make the decision to become a living kidney donor?
This decision might be made with the recipient role in mind. Donors can be family members, friends, or even altruistic unknown others. A comparison of the relationship between the donors and recipients going through the evaluation process and those rated as desirable candidates by demographically others can shed light on this issue.

It is common practice for transplant programs to accept living, unrelated donors, which was not the case in the past (26). Living related donors, however, are still most common; the largest number of living kidney transplants since 1988 have come from full siblings, followed by children and then parents of recipients. Spouses are also a common source of donated kidneys (1). The final research question examines these relationships:

RQ7: What is the comparison between the role relationships of donors and recipients for living kidney donor volunteers and a demographically matched sample?

The method and results of tests of these research questions are presented next.

\section{Method}

Participants

There were 82 participants. Forty-five had agreed to donate their kidney, and they participated while completing their final evaluation clinic to become living kidney donors. Of the participants who reported demographic characteristics, $53.3 \%$ were women and $31.1 \%$ men. Ages ranged from 21 to $64 \mathrm{yr}$, with an average of $44.65 \mathrm{yr}(\mathrm{SD}=12.8)$. The breakdown of ethnicity for the 31 respondents who reported it was 25 European Americans (80.6\%), four African Americans (8.9\%), and one Native American (3\%). Some of the living donor volunteers did not answer all demographic questions; $31.1 \%$ of donors did not indicate ethnicity and $15.6 \%$ did not report gender.

The other 37 participants were in the matched demographic group. This group was matched on the gender, age, and ethnicity to the living kidney volunteers. There were 37 in the matched demographic group because 37 of the 45 donors provided all demographic information requested for matches on gender, age, and ethnicity. Women made up $62.2 \%$ of the matched participants and $37.8 \%$ were men. The age range was $21-63 \mathrm{yr}$, with an average age of $40.4 \mathrm{yr} \quad(\mathrm{SD}=12.8)$. Thirty identified as European American (81.1\%), three as African American (8.1\%), one as Native American $(2.7 \%)$, and three as other ethnicities $(8.1 \%)$. 
To determine that the two samples were, in fact, matched on sex, age, and ethnicity, chi-square test and $t$-tests were performed. The distribution of demographics across the two samples did not differ by gender, $\chi^{2}(1, \mathrm{~N}=75)=0.008, \mathrm{p}=0.93$, age, $t$ $(71)=-1.39, \mathrm{p}=0.168$ (two-tailed), or ethnicity, $\chi^{2}(4, N=68)=3.786, p=0.44$.

\section{Survey}

The human research and protection programs for each of the two universities involved in this research provided permission. Data were collected using paper and pencil surveys for individuals who had volunteered to be kidney donors. Donors completed the survey while they were attending appointments for their final clinical evaluations to engage in kidney donation at a large, reputable organ transplant center. Data collection took place during the time period of July to October, 2009. Forty-five individuals who volunteered to be donors were asked to participate and 43 agreed $(95.5 \%)$.

Data were collected for the matched demographic sample via quota sampling. Email requests were sent from the authors to individuals with the desired age, gender, and ethnicity. Respondents completed the surveys online using Websurveyor software. Demographics, compassionate love, family communication patterns, and volunteer activity questions were assessed in the survey for both groups. Additional questions were posed to the demographically matched sample about comfort with being asked directly to become a living donor, methods that they prefer to find out about the need of the potential recipient, whether they would make the decision to become a living kidney donor, and a rating scale of willingness to donate a kidney to others who hold different roles, such as particular family members, friends, coworkers, and acquaintances.

\section{Personal altruistic characteristic variables}

Compassionate love for humanity. Compassionate love for humanity was measured with five items from Santa Clara Brief Compassion Scale (27). Example items include "When I hear about someone (a stranger) going through a difficult time, I feel a great deal of compassion for him or her," "I tend to feel compassion for people, even though I do not know them," "One of the activities that provides me with the most meaning to my life is helping others in the world when they need help," and, "I often have tender feelings toward people (strangers) when they seem to be in need." These items were measured on a 7-point Likert-type scale where one was very strongly disagree and seven was very strongly agree. Confirmatory factor analysis (CFA) did not show an acceptable fit for the five items of brief compassion scale, Normed Fit Index (NFI) $=0.80$, Comparative Fit Index $(\mathrm{CFI})=0.82$, Incremental Fit Index $(\mathrm{IFI})=0.82$, Standardized Root Mean Square Residual $($ SRMR $)=0.13$. Removing one item (\#4, "I would rather engage in actions that help others, even though they are strangers, than engage in actions that would help me") improved the fit to acceptable levels, NFI $=0.95$, $\mathrm{CFI}=0.96, \quad$ IFI $=0.96, \quad \mathrm{SRMR}=0.058 . \quad$ The remaining four items had a reliability of 0.84 (Cronbach's $\alpha$ ).

Volunteer activities. Participants were asked to list volunteer activities with the following: "We are interested in the volunteer behaviors in which you engage. Please list any that come to mind including, but not limited to community volunteer activities, charitable giving, blood donation, bone marrow registry or donation, organ donor registry, recycling, church, and anything else that you can think of. Please list the volunteer behaviors below."

Volunteer activities were coded in terms of the umbrella categories of ideology related activities (including church and political activities), health related activities (including blood donation and helping with health related causes), neighborhood and community assistance activities (including helping the homeless, charitable giving, and recycling), activities that help children (e.g., volunteering in schools and coaching children's sports teams), and an "other" category for activities that did not fit elsewhere. Two coders established intercoder reliability on $10 \%$ of the sample (Cohen's Kappa $=0.91)$, and each independently coded half of the remaining activities.

\section{Communication variables}

Family communication patterns. Family communication patterns were measured with Ritchie and Fitzpatrick's (23) revised version of the Family Communication Pattern scale. A previous study conducted a CFA on the family communication scale and reported an acceptable fit for a reduced number of items (21). Fifteen of those items were used for this study. CFA did not show an acceptable fit for a two-factor model with 15 items, $\mathrm{NFI}=0.85, \quad \mathrm{CFI}=0.90, \quad \mathrm{IFI}=0.91, \quad \mathrm{SRMR}=$ 0.11 . Removing two items improved the fit to acceptable levels, NFI $=0.90, \quad$ CFI $=0.94, \quad$ IFI $=0.94$, SRMR $=0.077$. Reliabilities were 0.94 on the eight 
items for conversation-oriented family communication and 0.86 for the five items on conformity-oriented family communication.

Comfort with being asked directly to become a living kidney donor. A three-item scale was created for this study that included the following items: I would be comfortable if I was asked directly to donate my kidney, I would be uneasy if I was asked directly to donate my kidney, and I would feel unsettled if I was asked directly to donate my kidney. The second and third items were reflected, and the reliability for the scale is $\alpha=0.94$.

\section{Preference for learning of need}

Respondents in the volunteer group indicated whether they had been asked directly or whether they had found out about the need indirectly and then volunteered. Respondents in the demographically matched sample answered five items that were created for this study to assess the communication means through which they would prefer to learn of the need for kidney donation. These items used the stem, "If a close other was in need of a kidney transplant, how would you like to learn of the need?" Participants were asked to indicate on a 7-point Likert scale from strongly disagree to strongly agree for each of the following options: (i) Direct request from them to me, (ii) Learning about the need indirectly and having option to volunteer without a direct request, (iii) I would not want to know, (iv) Mass letter/email, and (v) Word of mouth through family and friends.

\section{Donor decision factors}

Decision to donate. One item was asked of respondents in the demographically matched sample with a yes or no answer format: "Would you ever considering donating one of your kidneys?"

Decision to donate to a particular recipient. If the answer to the last question was yes, respondents were asked to assess the following question: "To whom would you consider donating your kidney?" Seven-point Likert-type response formats of strongly disagree to strongly agree were provided for each of the following types of roles: (i) spouse/partner, (ii) parent, (iii) grandparent, (iv) sibling, (v) uncle/aunt, (vi) cousin, (vii) friend, (viii) other family member, (ix) coworker, (x) acquaintance.

Volunteers were asked their role relationship with the intended recipient. The comparison that is made is therefore between those who have chosen a recipient who occupies a particular role and the ratings of likelihood that the demographically matched sample members believe that they would donate a kidney to people who occupy that role in their lives.

\section{Results}

\section{Personal characteristics}

RQ1: compassionate love for humanity. Donors had significantly higher scores $(\mathrm{M}=5.92, \mathrm{SD}=0.71)$ on the compassion scale than the demographically matched sample $(\mathrm{M}=5.56, \quad \mathrm{SD}=0.68), \quad t$ $(78)=2.31, p=0.02, \eta^{2}=0.06($ Table 1$)$.

RQ2: volunteer activities. Independent sample $t$ tests were used to examine whether the donors and matched sample participants differed in volunteer activities (Table 2). $T$-tests were used to examine whether there were differences for each category of volunteer activity as well as the overall categories for number of volunteer activities. There were significant differences between the two groups; for each difference, the matched respondents had a larger number of volunteer activities.

The matched respondents reported a larger number of recycling activities $(\mathrm{M}=0.54, \mathrm{SD}=0.51)$ than the donors $[\mathrm{M}=0.27, \quad \mathrm{SD}=0.45, \quad t$ $(80)=2.571, \mathrm{p}<0.05]$, a larger number of school and education activities $(\mathrm{M}=0.78, \mathrm{SD}=1.36)$ than the donors $[\mathrm{M}=0.18, \quad \mathrm{SD}=0.44, \quad t$ $(80)=2.606, p<0.05]$, a greater number of charity activities $(\mathrm{M}=0.46, \mathrm{SD}=0.61)$ than the donors $[\mathrm{M}=0.16, \quad \mathrm{SD}=0.37, \quad t(80)=2.803, \mathrm{p}<0.01]$, and a greater number of activities for neighborhood, friend, or family assistance $(\mathrm{M}=0.3$, $\mathrm{SD}=0.57)$ than the donors $[\mathrm{M}=0.07, \mathrm{SD}=0.33$,

Table 1. Means, standard deviations, and T-statistics for donors vs. demographically matched others for compassion, conversation family orientation, and conformity family orientation

\begin{tabular}{|c|c|c|c|c|c|c|}
\hline & Mean & SD & $T$-value & df & $\mathrm{p}$-Value & $\eta^{2}$ \\
\hline \multicolumn{7}{|l|}{ Compassion } \\
\hline Donors & 5.92 & 0.71 & 2.31 & 78 & 0.02 & 0.06 \\
\hline $\begin{array}{l}\text { Demographically } \\
\text { matched others }\end{array}$ & 5.56 & 0.68 & & & & \\
\hline \multicolumn{7}{|c|}{$\begin{array}{l}\text { Conversation-oriented } \\
\text { family communication }\end{array}$} \\
\hline Donors & 5.39 & 1.21 & 1.37 & 78 & 0.18 & 0.02 \\
\hline $\begin{array}{l}\text { Demographically } \\
\text { matched others }\end{array}$ & 5.04 & 1.05 & & & & \\
\hline \multicolumn{7}{|c|}{$\begin{array}{l}\text { Conformity-oriented } \\
\text { family communication }\end{array}$} \\
\hline Donors & 4.68 & 1.1 & 0.27 & 78 & 0.79 & 0 \\
\hline $\begin{array}{l}\text { Demographically } \\
\text { matched others }\end{array}$ & 4.75 & 1.24 & & & & \\
\hline
\end{tabular}


Table 2. Volunteer activities by donors and matched sample

\begin{tabular}{|c|c|c|c|c|c|}
\hline & \multicolumn{2}{|c|}{ Donors } & \multicolumn{2}{|c|}{$\begin{array}{l}\text { Matched } \\
\text { respondent }\end{array}$} & \multirow[b]{2}{*}{$t$-Value } \\
\hline & Mean & SD & Mean & SD & \\
\hline \multicolumn{6}{|l|}{$\begin{array}{l}\text { Individual } \\
\text { categories }\end{array}$} \\
\hline $\begin{array}{l}\text { Church related } \\
\text { activities }\end{array}$ & 0.42 & 0.62 & 0.84 & 1.17 & 1.951 \\
\hline $\begin{array}{l}\text { Bodily donation } \\
\text { activities }\end{array}$ & 0.64 & 0.91 & 0.65 & 0.63 & 0.025 \\
\hline Recycling & 0.27 & 0.45 & 0.54 & 0.51 & $2.571^{\star}$ \\
\hline $\begin{array}{l}\text { School education } \\
\text { activities }\end{array}$ & 0.18 & 0.44 & 0.78 & 1.36 & $2.606^{\star}$ \\
\hline $\begin{array}{l}\text { Community } \\
\text { service }\end{array}$ & 0.38 & 0.68 & 0.78 & 1.36 & 1.656 \\
\hline Sports coaching & 0.04 & 0.21 & 0.08 & 0.28 & 0.683 \\
\hline Politics & 0.07 & 0.45 & 0.05 & 0.23 & -0.155 \\
\hline Charity & 0.16 & 0.37 & 0.46 & 0.61 & $2.803^{\star *}$ \\
\hline Helping children & 0.09 & 0.36 & 0.03 & 0.16 & -1.034 \\
\hline $\begin{array}{l}\text { Mentoring non- } \\
\text { children }\end{array}$ & 0.02 & 0.15 & 0.16 & 0.55 & 1.494 \\
\hline $\begin{array}{l}\text { Neighborhood, } \\
\text { friend, or family } \\
\text { assistance }\end{array}$ & 0.07 & 0.33 & 0.30 & 0.57 & $2.176^{\star}$ \\
\hline Helping homeless & 0.07 & 0.21 & 0.22 & 0.53 & 1.844 \\
\hline $\begin{array}{l}\text { Helping health } \\
\text { related causes }\end{array}$ & 0.29 & 0.76 & 0.22 & 0.53 & -0.491 \\
\hline $\begin{array}{l}\text { Other volunteer } \\
\text { activity }\end{array}$ & 0.29 & 0.25 & 0.05 & 0.23 & -0.235 \\
\hline $\begin{array}{l}\text { Total number of } \\
\text { volunteer } \\
\text { activities }\end{array}$ & 3.49 & 1.99 & 4.62 & 2.72 & $2.108^{\star}$ \\
\hline \multicolumn{6}{|l|}{$\begin{array}{l}\text { Summed } \\
\text { categories }\end{array}$} \\
\hline Category: ideology & 0.49 & 0.73 & 0.89 & 1.17 & 1.821 \\
\hline $\begin{array}{l}\text { Category: health } \\
\text { related }\end{array}$ & 0.93 & 1.27 & 0.86 & 0.86 & -0.291 \\
\hline $\begin{array}{l}\text { Category: } \\
\text { neighborhood, } \\
\text { community, } \\
\text { helping needy }\end{array}$ & 0.93 & 1.16 & 2.46 & 1.80 & $4.449^{\star \star *}$ \\
\hline $\begin{array}{l}\text { Category: helping } \\
\text { children }\end{array}$ & 0.31 & 0.63 & 0.89 & 1.54 & $2.147^{*}$ \\
\hline Category: other & 0.07 & 0.25 & 0.05 & 0.02 & -0.235 \\
\hline
\end{tabular}

$* p<0.05 ; * p<0.01 ; * * * p<0.001$

$t(80)=2.176, \mathrm{p}<0.05]$. Additionally, the summed value of all volunteer activities was greater for matched participants $(\mathrm{M}=4.62, \mathrm{SD}=2.72)$ than for donors $[\mathrm{M}=3.49, \mathrm{SD}=1.99, t(80)=2.108$, $\mathrm{p}<0.05]$. The matched respondents reported a larger number of activities $(\mathrm{M}=2.46, \mathrm{SD}=1.8)$ for the categories of neighborhood, community, and helping the needy, than did donors $[\mathrm{M}=0.93$, $\mathrm{SD}=1.16, t(80)=4.449, \mathrm{p}<0.001]$.

\section{Communication characteristics}

RQ3: conversation and conformity family communication patterns. Donors $(\mathrm{M}=5.39, \mathrm{SD}=1.21)$ and demographically matched others $(\mathrm{M}=5.04$, $\mathrm{SD}=1.05)$ did not differ in conversation-oriented family communication, $t(78)=1.37, \quad \mathrm{p}=0.18$, $\eta^{2}=0.02 \quad$ (Table 1). Also, donors $(\mathrm{M}=4.68$, $\mathrm{SD}=1.10)$ and demographically matched others $(\mathrm{M}=4.75, \mathrm{SD}=1.24)$ did not differ in conformity-oriented family communication, $t(78)=0.27$, $\mathrm{p}=0.79, \eta^{2}=0.00$ (Table 1$)$.

RQ4: comfort in being asked directly. Demographically matched others were given the three-item scale on comfort with being asked to be a kidney donor directly, the mean of which was 4.14 $(\mathrm{SD}=1.15)$. The scale mean was compared with the mid-point of the scale by a one-sample $t$-test. The results of this test revealed that the mean of the scale (4.14) was not significantly different than the mid-point of the scale $(4), t(37)=1.38$, $\mathrm{p}=0.09$. However, when the mean of the item "I would feel comfortable if I was asked directly to donate my kidney" $(\mathrm{M}=4.31, \mathrm{SD}=1.21)$ was compared with the mean of the item "I would feel unsettled if I was asked directly to donate my kidney" $(\mathrm{M}=3.97, \mathrm{SD}=1.18)$, a significant $t$-value did emerge, $t(36)=2.53$, $\mathrm{p}=0.016$. These results indicate that the mean of the scale is not significantly different than the neutral mid-point of the scale, but respondents reported feeling significantly more comfortable than unsettled with the idea of being asked directly to donate.

RQ5: methods of notification of need. Data from donor volunteers indicated that only two donors $(4.7 \%)$ reported that they were asked directly, while the remaining donors reported volunteering to donate without being asked $(95.3 \%)$.

Demographically matched others indicated a strong preference for being directly asked to donate $(\mathrm{M}=5.35, \mathrm{SD}=1.29)$ and for learning indirectly about the need and having the option to volunteer $(\mathrm{M}=4.89, \mathrm{SD}=1.24)$. The means of these items are not significantly different than one another, $t(35)=1.31, \quad \mathrm{p}=0.197$. These respondents rated their desire to find out via word of mouth at the mid-point of the scale $(\mathrm{M}=4.06, \mathrm{SD}=1.62)$, which was significantly lower than being asked directly, $t(35)=3.44$, $\mathrm{p}=0.002$, or for learning indirectly and having the option to volunteer, $t(35)=2.86, \mathrm{p}=0.007$. Respondents indicated that they would not like to hear from a mass letter or email $(\mathrm{M}=2.78$, $\mathrm{SD}=1.72$ ), nor would they not want to know about the need at all $(\mathrm{M}=2.34, \mathrm{SD}=1.35)$. Finding out through word of mouth was rated significantly more highly than finding out about 
the need through a mass letter or email, $t(35)=4.60, \mathrm{p}<0.01$, or not finding out at all, $t(35)=4.71, \mathrm{p}=0.0001$.

RQ6: proportion who would donate. Of the 37 respondents in the demographically matched sample, $68 \%$ reported that they would consider donation.

RQ7: recipient roles. Recipient roles were identified for 43 of the living kidney donor volunteers. The vast majority of recipients were family members (31 people or $72 \%$ ), followed by friends and acquaintances ( 11 people or $24.4 \%$ ), and one altruistic donor who did not know the recipient. The breakdown of recipients by family role are spouse/ significant other ( 8 or $18.6 \%$ ), parent (8 or $18.6 \%$ ), sibling ( 7 or $16.3 \%)$, and other family members (8 or $18.6 \%$ ) (Table 3 ).

Demographically matched others also indicated strong willingness to donate a kidney to spouses $(\mathrm{M}=6.88, \quad \mathrm{SD}=0.33), \quad$ parents $\quad(\mathrm{M}=6.52$, $\mathrm{SD}=1.05)$, and siblings $(\mathrm{M}=6.6, \mathrm{SD}=0.76)$. The next most likely recipients of the demographically matched sample are friends $(\mathrm{M}=5.54$, $\mathrm{SD}=1.10)$ and other family members in general $(\mathrm{M}=5.19, \mathrm{SD}=1.28)$ or in particular, such as grandparents $(\mathrm{M}=5.39, \mathrm{SD}=1.67)$, uncles and aunts $(\mathrm{M}=5.29, \quad \mathrm{SD}=1.76), \quad$ and cousins $(\mathrm{M}=5.25, \mathrm{SD}=1.54)$. The least likely recipients were coworkers $(\mathrm{M}=4.46, \quad \mathrm{SD}=1.50)$ and acquaintances $(\mathrm{M}=4.09, \mathrm{SD}=1.59)($ Table 3$)$.

Table 3. Roles of recipients by donors and matched sample

\begin{tabular}{|c|c|c|c|}
\hline \multirow{3}{*}{$\begin{array}{l}\text { Role of } \\
\text { Recipient }\end{array}$} & \multicolumn{2}{|c|}{ Donors } & $\begin{array}{c}\text { Matched } \\
\text { sample }\end{array}$ \\
\hline & \multicolumn{2}{|c|}{$\begin{array}{l}\% \text { of people } \\
\text { receiving } \\
\text { kidney }\end{array}$} & \multirow{2}{*}{$\begin{array}{l}\text { Mean score } \\
\text { for considering } \\
\text { donation to } \\
\text { each role }\end{array}$} \\
\hline & $\mathrm{N}$ & $\%$ & \\
\hline Spouse & 8 & 18.6 & 6.88 \\
\hline Parent & 8 & 18.6 & 6.52 \\
\hline Sibling & 7 & 16.3 & 6.6 \\
\hline Grandparent & 0 & 0.0 & 5.39 \\
\hline Uncle or aunt & 0 & 0.0 & 5.29 \\
\hline Cousin & 0 & 0.0 & 5.25 \\
\hline Friend & 11 & 25.6 & 5.54 \\
\hline Coworker & 0 & 0.0 & 4.46 \\
\hline Acquaintance & 0 & 0.0 & 4.09 \\
\hline $\begin{array}{l}\text { Other family } \\
\text { member }\end{array}$ & 8 & 18.6 & 5.1875 \\
\hline \multirow[t]{2}{*}{ Stranger } & 1 & 2.3 & NA \\
\hline & $N=43$ & & $N=37$ \\
\hline
\end{tabular}

\section{Post hoc analysis}

A moderated regression analysis was conducted to see if donors and demographically matched others differed in the way conversation-oriented and conformity-oriented family communication patterns were related to compassionate love. Participant type was dummy coded with $0=$ donors and $1=$ demographically matched others. Conversation-oriented and conformityoriented family communication patterns were mean-centered before being multiplied with the dummy variable, type, to avoid unnecessary multicollinearity. For example, the product term of conversation-oriented family communication and type provided a test for type as the moderator of the relationship between conversation-oriented family communication and compassionate love. A hierarchical regression analysis included type (the dummy-coded variable) and two types of family communication in the first block of the analysis. The second-order predictor terms (conversation-orientation $\times$ type and conformityorientation $\times$ type) were included in the second block. The third-order predictor term (conversation-orientation $\times$ type and conformity-orientation $\times$ type) was included in the third block.

The three predictors explained a significant amount of variance in compassionate love, $F(3$, $76)=3.03, \mathrm{p}=0.03$, adj. $R^{2}=0.07$. Type was significant, $\beta=-0.23, \quad \mathrm{p}=0.04$, indicating that demographically matched others had lower compassionate love than donors. Conversationoriented family communication, $\beta=0.18$, $\mathrm{p}=0.11$, and conformity-oriented family communication, $\beta=0.14, p=0.21$, were not significantly related to compassionate love.

The two second-order predictors did not explain a significant amount of variance in compassionate love, $F_{\text {change }}(2,74)=0.89, \mathrm{p}=0.42$, $R_{\text {change }}^{2}=0.02$. The two-way interaction of conversation orientation and type was not significant, unstandardized coefficient $(B)=-0.05, \mathrm{SE}=0.15$, $\mathrm{p}=0.71$. The two-way interaction of conformity orientation and type was not significant, $B=0.17$, $\mathrm{SE}=0.14, \mathrm{p}=0.71$. These results indicated that donors and demographically matched others did not differ in the relationships between conversation orientation and compassion and between conformity orientation and compassion.

The third-order predictor did not explain a significant amount of variance in compassionate love, $F_{\text {change }}(1,73)=0.27, \mathrm{p}=0.61, R_{\text {change }}^{2}=0.00$. The three-way interaction of conversation orientation, conformity orientation, and type was not significant, $B=0.05, \mathrm{SE}=0.10, \mathrm{p}=0.61$. 
Therefore, no interactions were identified with regard to the effect of sample type or family communication style on compassionate love. The only effect on compassionate love was sample type, which accounted for $7 \%$ of the variance, with donor volunteers evidencing significantly higher compassionate love than those in the matched sample.

\section{Discussion}

This research was undertaken to determine whether personal and communication characteristics of living kidney donor volunteers could be distinguished from a set of demographically matched others. The questions addressed whether particular levels of love for humanity, volunteer activities, and family communication patterns would characterize the group of living kidney donor volunteers in contrast to the demographically matched others. If differences were found, those in need of kidneys could be taught to identify potential donors by those means. In addition, the demographically matched group was surveyed to determine their comfort with being asked directly to donate a kidney and their preferred methods of learning about the need of another for a kidney. While the living donor volunteer group noted that very few had been asked to donate directly, the matched sample indicated that they would be equally comfortable with being asked directly or finding out via the communication network that is shared by the donor and the recipient. This information will be helpful to potential recipients as they decide how to let others know about their need for a kidney.

Role relationships of recipients of the volunteer kidney donors were compared with ratings by the demographically matched sample of willingness to donate to people who occupy particular roles. Both groups indicated high willingness to donate to family members followed by friends. These findings allow potential recipients to see the role relationships that are most frequent between donors and their recipients, and also, show ratings of likelihood of donation to members of certain roles by the demographically matched others.

Findings indicated that donors had significantly higher scores for self-rated compassion, while nondonors reported significantly more volunteer activities. The higher self-ratings of compassion for the living kidney donor volunteers can possibly be explained by the fact that donation was focal in their minds at the final evaluation clinic before they gave a kidney. The extensive list of volunteer activities generated shows that, across the board, the demographically matched sample engaged in more volunteerism. This finding can be used to show potential kidney recipients that they do not need to look for donors who are "super-volunteers," but rather they can look to people who perform a lower number of volunteer duties to become donors.

Donors and non-donors did not differ in conversation or conformity orientations of family communication styles. In addition, communication style did not interact with the type of respondent to predict compassion. This finding shows that living kidney donors come from families with both conformity and conversation communication styles.

Only $4.7 \%$ of donor volunteers reported being asked to donate directly. Matched respondents reported feeling more comfortable than unsettled with the idea of being asked directly and indicated an equal preference for learning of the need directly or indirectly, giving them the option to volunteer. These findings underscore the widespread reluctance by those needing kidneys to ask potential donors directly. While the results show that the demographically matched sample was more comfortable than unsettled with the idea of a direct request, the other findings indicate that finding out in an indirect way and being able to volunteer is equally preferable. While this finding suggests that potential recipients can use either direct or indirect request, it is still unknown whether the direct or indirect method is more likely to lead to donation.

The majority of donors were giving to family members and friends, and the matched sample indicated greater willingness to donate to immediate family members, followed by friends. These findings indicate that those in need of a kidney should look to family members and friends for a donor.

These findings help in answering the call from Waterman et al. (8), who noted that better education about asking for donations, donor motivations, and the transplant experience would benefit those considering living donation.

\section{Limitations}

Letine et al. (28) examined records for 4650 living kidney donors over a 20 -yr period from $1987-$ 2007. They reported that $76.3 \%$ were white, $13.1 \%$ black, $8.2 \%$ Hispanic, and $2.4 \%$ another race or ethnic group. The non-white participants in this study make up $17.6 \%$ of the sample, thus there is lower non-white representation here than in the make-up of past living kidney donors. However, $17.6 \%$ non-white respondents is a significantly higher rate than in other current large-scale donor evaluation efforts, in which rates between $6 \%$ and $11 \%$ have been predicted. 


\section{Conclusion}

This study attempts to understand living kidney donor volunteers' personal characteristics, communication, and decisions to donate by comparing them to a demographically matched quota sample. The findings should be useful to those working with potential kidney recipients as they train them in the best ways to request donation.

\section{Acknowledgements}

This work was made possible by the generous support of the Gift to establish the Craig Peters Organ Donation Fund.

\section{References}

1. Optn.transplant.hrsa.gov [Internet]. Organ Procurement and Transplantation Network National Data. Available from: http://optn.transplant.hrsa.gov/latestData/step2. asp? (Retrieved 28 October 2010, cited 11 September 2011).

2. Meier-Kriesche H, Kaplan B. Advantages of living donor kidney transplantation in the current era. In: Gaston RS, Wadstrom J eds. Living Donor Kidney Transplantation: Current Practices, Emerging Trends, and Evolving Challenges. London: Taylor \& Francis, 2005: 9.

3. Rodrigue J, Cornell D, Lin J, Kaplan B, Howard R. Increasing live donor kidney transplantation: a randomized controlled trial of a home-based educational intervention. Am J Transplant 2006: 7: 394.

4. Reese P, Shea J, Berns J et al. Recruitment of live donors by candidates for kidney transplantation. Clin J Am Soc Nephrol 2008: 3: 1152.

5. Kranenburg LW, Zuidema WC, Weimar W, Hilhorst MT, IJzermans JN, Passchier J, et al. Psychological barriers for living kidney donation: how to inform the potential donors? Transplantation 2007: 84: 965.

6. Smith SW, Nazione S, Lauckner C, Clark-Hitt R, Sung R, Leichtman A. Living kidney donor decision making and communication. J Health Commun 2011: 16: 870.

7. Live Organ Donor Consensus Group. Consensus statement on the live organ donor. JAMA 2000: 284: 2919.

8. Waterman AD, Barrett AC, Stanley SL. Optimal transplant education for recipients to increase pursuit of living donation. Prog Transplant 2008: 18: 55.

9. Waterman AD, Stanley Sl, Covelli T, Hazel E, Hong BA, BRENNAN DC. Living donation decision making: recipients' concerns and educational needs. Prog Transplant 2006: 16: 17.

10. Stothers L, Gourlay W, Liu L. Attitudes and predictive factors for live kidney donation: a comparison of live kidney donors versus nondonors. Kidney Int 2005: 67: 1105.
11. Kopfman JE, Smith SW. Understanding the audiences of a health communication campaign: a discriminant analysis of potential organ donors based on intent to donate. $\mathbf{J}$ Appl Commun Res 1996: 24: 33.

12. Morgan SW, Miller JK. Communicating about gifts of life: the effect of knowledge, attitudes and altruism on behavior and behavioral intentions regarding organ donation. J Appl Commun Res 2002: 30: 163.

13. Dixon DJ, Авbey SE. Religious altruism and the living organ donor. Prog Transplant 2003: 13: 169. javascript: PopUpMenu2_Set(Menu14558630).

14. Eggeling C. The psychosocial implications of live-related kidney donation. EDTNA ERCA J 1999: 25: 19.

15. Mueller PS, Case EJ, Hook CC. Responding to offers of altruistic living unrelated kidney donation by group associations: an ethical analysis. Transplant Rev 2008: 22: 200.

16. Clary EG, SNyder M. The motivations to volunteer: theoretical and practical considerations. Curr Dir Psychol Sci 1999: 8: 156

17. Sмітн DH. Altruism, volunteers, and volunteerism. Nonpro Volunt Sec Q 1981: 10: 21.

18. Smith SW, Smith SL, Pieper KM et al. Altruism on American television: examining the prevalence of, and context surrounding, such acts. J Commun 2006: 56: 707.

19. Surman OS, Fukunishi I, Allen T, Hertl M. Live organ donation: social context, clinical encounter, and the psychology of communication. Psychosomatics 2005: 46: 1.

20. Sajuad I, Baines LS, Salifu M, Jindal RM. The dynamics of recipient-donor relationships in living kidney transplantation. Am J Kidney Dis 2007: 50: 834.

21. Park HS, Yun D, Smith SW, Morrison K. Family communication patterns and willingness to engage in family discussion about organ donation in the United States. Glob J Health Sci 2010: 2: 61.

22. Ritchie LD. Parents' workplace experiences and family communication patterns. Commun Res 1997: 24: 175.

23. Ritchie LD, FitzPatrick MA. Family communication patterns: measuring intrapersonal perceptions of interpersonal relationships. Commun Res 1990: 17: 523.

24. Koerner AF, Fitzpatrick MA. Toward a theory of family communication. Commun Theory 2002: 12: 70.

25. Pradel FG, Limcangco Mr, Mullins CD, Bartlett ST. Patients' attitudes about living donor transplantation and living donor nephrectomy. Am J Kidney Dis 2003: 41: 849.

26. Mandelbrot DA, Pavlakis M, Danovitch GM et al. The medical evaluation of living kidney donors: a survey of US transplant centers. Am J Transplant 2007: 10: 2333.

27. Hwang Jy, Plante T, Lackey K. The development of the Santa Clara brief compassion scale: an abbreviation of Sprecher and Fehr's compassionate love scale. Pastoral Psychol 2008: 56: 421.

28. Letine C, Schnitzler MA, Xiao H et al. Racial variation in medical outcomes among living kidney donors. N Engl J Med 2010: 363: 724. 